\title{
Work-life management for workforce maintenance: A qualitative comparative study
}

\author{
Rachel W.Y. Yee ${ }^{\text {a, }}$, Maria-Jose Miquel-Romero ${ }^{\mathrm{b}}$, Sonia Cruz-Ros ${ }^{\mathrm{c}}$ \\ ${ }^{\text {a }}$ Institute of Textiles and Clothing, The Hong Kong Polytechnic University, Hung Hom, Kowloon, Hong Kong \\ ${ }^{\mathrm{b}}$ Department of Marketing, University of Valencia, Valencia, Spain \\ ${ }^{\mathrm{c}}$ Deparment of Business Management, University of Valencia, Valencia, Spain
}

\section{A R T I C L E I N F O}

\section{Keywords:}

Workforce maintenance

Quality of working life

Well-being

Fuzzy-set qualitative comparative analysis

\begin{abstract}
A B S T R A C T
Nowadays, owing to the changing nature of the work environment, with its ever-increasing demands, the quality of working life and its relationship with the individual's wellbeing are recognized worldwide as vital for the workforce. This study analyzes the role of employees' perception of five quality of working life attributes (specifically workplace conditions, working life autonomy, corporate citizenship, remuneration, and workplace diversity and inclusion) in ensuring the individual's wellbeing focusing in particular on workers' perception of work-life balance, working life opportunities, and health and wellness. The results of the fuzzy-set qualitative comparative analysis reveal the same various configurations for the three outcomes that suggest a new perspective towards understanding the factors in employees' working life that enhance their wellbeing, and so improve workforce maintenance. The results have managerial implications related to work-life management for workforce maintenance.
\end{abstract}

\section{Introduction}

Improving the quality of working life has long been a goal of industrial relations and organizational research (e.g., Walton, 1974; Mickel \& Dallimore, 2009). Recent changes in the nature of work and personal environments have made achievement of this goal a higher priority (Grote \& Guest, 2017). From the perspective of the work environment, digitalization and flexible work arrangements, among other changes, have resulted in positive outcomes, but also in certain negative consequences that need consideration, as they can damage the individual's quality of personal and family life (Böhnke \& Cifuentes, 2018). Blurred work-personal life boundaries, and chronic health burnout (Kossek, 2016), or precarious employment often associated with a risk of exploitation, low earnings, or threats to work-life balance (Benavides et al., 2006; Sonnentag \& Binnewies, 2013) are some such consequences. From the perspective of the personal environment, new roles for men and women have appeared, family composition is more complex and diverse, and individuals' sexual, religious, and cultural diversity is more evident (Kossek, 2016; Oláh, Kotowska, \& Richter, 2018). Additionally, individuals now have more interest in devoting time to private issues, and in the quality of their lives outside of the organization for which they work (Guest, 2002). All these changes have significant implications for families, businesses, and society as a whole. In fact, from the perspective of the organization, the neglect of some of these characteristics can lead to workforce vulnerability and, consequently, high health care costs; high staff turnover at all organizational levels; and even, on occasion, organization-wide workforce crises (Lucas, Manikas, Mattingly, \& Crider, 2017). Improving the quality of working life is thus a high priority for today's organizations.

There are many studies that point to a positive relationship between quality of working life, improved employee's job satisfaction and organizational commitment (Daud, 2010; Mosadeghrad, 2013), and lower employee burnout, absenteeism, and turnover (Korunka, Hoonakker, \& Carayon, 2008). Such positive outcomes result in a more stable workforce, and improve business efficiency, productivity, and profitability, with positive consequences for business performance (May, Lau, \& Johnson, 1999). Accordingly, research suggests focusing on giving "primacy to improving the wellbeing of workers, rather than enhancing organizational performance", which was the original aim of the quality of working life movement promoted in the $60 \mathrm{~s}$ and $70 \mathrm{~s}$ (Grote \& Guest, 2017, p. 151).

To better understand workers' wellbeing, it is imperative to highlight the fact that the border between an individual's work and non-work life is not a sharp one, and in many cases, they overlap (Kossek, 2016).

\footnotetext{
* Corresponding author.

E-mail addresses: rachel.yee@polyu.edu.hk (R.W.Y. Yee), maria.j.miquel@uv.es (M.-J. Miquel-Romero), sonia.cruz@uv.es (S. Cruz-Ros).
} 
Work, family, and personal lives influence each other (Oláh et al., 2018). People will perform better as individuals and workers if, as part of an organization, their economic, social, and psychological needs are satisfied (Indumathy, 2012).

Wellbeing is a subjective perception (Cummins, 2005) that depends on several domains of life, such as personal relationships, achievements in life, future security, and personal health (Lau, Cummins, \& McPherson, 2005). The present research focuses on the aspects of the individual's wellbeing that are closely related to the individual's working life. We seek to understand what influences employees' perception of work-life balance, of their career opportunities, as well as of their health and wellness. Considering the criteria that influence quality of working life posited by Grote and Guest (2017), we investigate the role of the employee's perception of five different working life attributes: workplace conditions, working life autonomy, corporate citizenship, remuneration, and workplace diversity and inclusion. The aims of this research are two-fold: to explore those qualities of working life criteria that can be managed, so as to improve the quality of working life, and to investigate the contribution of those factors to the three domains of the individual's wellbeing under consideration: perception of work-life balance, career opportunity, and health and wellness. The findings of this research should provide companies with valuable insights, enabling them to adequately manage their workforce in ways that favor individual wellbeing and retain employees.

With these aims in mind, fuzzy-set qualitative comparative analysis (fsQCA) is performed on data collected from international firms that usually attribute high importance to the quality of working life and wellbeing of their employees. This responds to the call of Grote and Guest (2017) for more research related to working life quality management with sufficient academic rigor and practical relevance. The methodology adopted in this study follows a complementary approach to the ones performed in other papers that sheds light on the determinants of the quality of working life, and their relationship to the dimensions of the individual's wellbeing.

The remainder of this paper is organized as follows. In section 2, the relevant literature in the management and organizational field is reviewed. The review covers the three analyzed aspects of an individuals' wellbeing, and the factors that a company can influence to improve the quality of their working life. In section 3, the methodological details are presented, followed by the analytical results in section 4. The paper ends with an in-depth discussion and implications of our findings in section 5 .

\section{Literature review}

Organizational interventions in working life have been considered in a number of contexts such as vocational and industrial behavior (Delanoeije, Verbruggen, \& Germeys, 2019), work-life leadership in human capital development (Hammond, Clapp-Smith, \& Palanski, 2017), and work-life aspiration and autonomy in organizational culture changes (Driedonks, Gevers, \& van Weele, 2010; Kossek, Hammer, Kelly, \& Moen, 2014). Most work-life research considers employees in many kinds of physical and social circumstances, and points to management interventions that can facilitate achieving a balance of the personal and the professional spheres and, as a result, a stable workforce.

This section reviews the related concepts of work-life policies that can improve the quality of working life under the rubrics of workforce maintenance; it covers workplace conditions, working life autonomy, corporate citizenship, remuneration, and workplace diversity and inclusion. Work-life management intervention aims for outcomes that are congruent with the employees' interests in relation to their life within and outside work. Employees' perceived satisfaction with any of their workplace conditions can affect their personal wellbeing. Specifically, the perceptions contributing to the individual's wellbeing that this study considers are perceptions of work-life balance, of working life opportunities, and of health and wellness. These variables and outcomes are discussed in detail below.

\subsection{Areas of the individual's wellbeing related to the quality of working life}

\subsubsection{Perception of work-life balance}

Hill, Hawkins, Ferris, and Weitzman (2001, p. 49) define work-life balance "as the degree to which an individual is able to simultaneously balance the temporal, emotional, and behavioral demands of both paid work and family responsibilities". It is not a new topic, as previous research has investigated the rationales and theories of worklife balance for devising policies and management solutions to mitigate the conflict between work and life spaces (Delanoeije et al., 2019).

Flexibility in timing and location of work, derived from the sophisticated communication platforms present in many companies can, at first sight, appear to favor a work-life balance (Hill et al., 2001). However, research finds that employees perceive that one effect of such flexibility is that aspects of their work and non-work lives become increasingly blurred. The result is an ambiguity between work and personal life that disrupts employees' efficiency at work and, simultaneously, their satisfaction with life (Dumas \& Sanchez-Burks, 2015; Carlson, Thompson, \& Kacmar, 2019). Nevertheless, another perspective argues that work and life interests are inseparable, and that institutions should offer a high level of work flexibility over the course of an individual's working career, with only a limited restriction in an individual's personal life (Tomlinson, Baird, Berg, \& Cooper, 2018). Clearly, these two perspectives underlie different management intervention approaches that help employees control intertwining work and life role domains. Regardless of the perspective adopted, employees' ability to control their schedule is crucial to avoiding an over-irruption across work-life space that can lead to a tense, antithetical workerorganization relationship (Haar, Russo, Suñe, \& Ollier-Malaterre, 2014; Kossek, Ruderman, Braddy, \& Hannum, 2012). Therefore, work-life balance requires that management facilitate appropriate career commitment, without compromising employees' personal interests and health.

\subsubsection{Perception of working life opportunities}

Working life opportunities can be defined as work-related goals and career aspirations. Working life opportunities address the mutuality of career prospects and personal interests. Applied psychology has identified certain factors that carry significant mediating, or moderating, effects on working life opportunities. These factors cover career and personal aspects; for example, judgement of work-life possibilities (Kim, Fouad, \& Lee, 2018), costs and benefits at work (Creed, Hood, \& Hu, 2017; Shepley et al., 2017), self-efficacy (Alisic \& Wiese, 2020), and selfregulation (Napolitano, Hoff, Ming, Tu, \& Rounds, 2020). Likewise, research on organizational psychology finds that two complementary factors, namely personality (Ilies \& Judge, 2003) and work-life situation (Unanue, Vignoles, Dittmar, \& Vansteenkiste, 2016), determine career goals and aspiration. Working life opportunities are perceived as satisfactory when these factors are congruent (Unanue et al., 2016) and, in general, when career prospects and personal interests are achieved at the same time.

\subsubsection{Perception of health and wellness}

A routine work schedule would seem impossible in today's global business environment, in which business activities are conducted round the clock. Employees are expected to respond rapidly, or even instantly, to work-related demands from their 'virtual' colleagues (Makarius \& Larson, 2017). Physical and emotional stresses encountered at work can drain employees' energy and sap their enjoyment of life (Creed et al., 2017). Baicker, Cutler, and Song (2010) point out that irregular work practices pose a number of deleterious health and wellness impacts such as loss of enthusiasm for work, perceived devaluation of personal life, and escalating costs of healthcare-related expenses for organizations and 
society. Current applied research into work-life health and wellness has investigated management solutions (e.g., Baicker et al., 2010; Burton, 2010; Hoert, Herd, \& M., \& Hambrick, M., 2018). Burton (2010) surveyed key wellness domains, including psychological and physical work environments, corporate-community involvement, and health resources. His key finding is that employees' perception of their health and wellness is optimized when companies take both the work environment, and the health and wellbeing of their employees, into consideration.

\subsection{Quality of working life factors}

\subsubsection{Workplace conditions}

Workplace conditions encompass a broad range of circumstances that help workers perform work-related tasks. Prior research shows that appropriate workplaces and facilities can help employees boost their performance and productivity. Further, satisfaction with workplace conditions can trigger a positive psychological effect on employees' perceived privacy (Kim \& de Dear, 2013), dignity (Lucas, Kang, \& Li, 2013), ability to deal with excessive stimulation (Maher \& von Hippel, 2005), and socializing behavior in the workplace (Iachini et al., 2016). Accordingly, satisfaction with workplace conditions can promote psychological wellbeing, interpersonal relationships, and a positive impact on work efficiency.

\subsubsection{Working life autonomy}

Working life autonomy is a characteristic of workplace flexibility, involving flexibility in work arrangements and in work processes. Research on the topic supports a positive relationship between workplace flexibility, quality of personal life (Subramaniam, Tan, Maniam, \& Ali, 2013), and work-life balance (Hill et al., 2001), demonstrating that businesses, as well as the personal and family life of employees, benefit from such flexibility.

Autonomy necessarily accompanies control, but it does not mean that autonomy in the workplace gives workers extraordinary authority or superordinate control (Kossek et al., 2014). Rather, it means that workers have discretion with regard to work schedules and styles, which enables them to respond unexpected needs in the course of their life (Driedonks et al., 2010). In fact, total working life autonomy could well lead to employees' pressuring themselves to work anytime and/or anywhere outside the workplace (Hill et al., 2001; Eurofound., 2015). Employees, given total work-life autonomy, and in the absence of employer engagement, might not be able to limit their working hours. From an industrial psychology perspective, working life autonomy can be regarded as effective only when employees and employers reach a consensus on working life norms, and on being able to adjust workplace flexibility policies as required (Driedonks et al., 2010; Prem, Kubicek, Diestel, \& Korunka, 2016).

\subsubsection{Corporate citizenship}

Corporate citizenship, or corporate social responsibility, is a management value that concerns corporate behavior insofar as it is responsible for the wellbeing of employees, and beneficial to groupings both within the corporation and to society as a whole (Podsakoff, Mackenzie, Paine, \& Bachrach, 2000; Singhapakdi, Lee, Sirgy, \& Senasu, 2015). Recognized corporate citizenship builds up a positive organizational identity and is therefore attractive to both prospective employees and business stakeholders (Turban \& Greening, 1997). Furthermore, corporate citizenship recognizes a mutuality between success at work and contribution to the wider community. It implies that an appropriate coordination of an individual employee's multiple roles at work and in life can lead to repercussions that benefit others (Valentine, Godkin, Fleischman, \& Kidwell, 2011). From the perspective of socialenvironmental psychology, this mutuality is regarded as a positive spillover effect between work and life, or between career and family (Grzywacz \& Marks, 2000; Hanson, Hammer, \& Colton, 2006). Succinctly, organizations that advocate corporate citizenship attempt to nurture cross-domain leadership and a loyal workforce (Edwards \& Rothbard, 2000; Hammond et al., 2017).

Employees' perception that their organization is a genuine corporate citizen enhances their self-esteem, improves their affective wellbeing, and positively influences their expectations of career success. They become more committed to the organization and their performance improves, benefiting the entire organization (Maignan \& Ferrell, 2001a; Rego, Leal, Cunha, Faria, \& Pinho, 2010; Lin, Tsai, Joe, \& Chiu, 2012).

\subsubsection{Remuneration}

The relevance of remuneration as a working life management criterion resides in its support for the employee's lifestyle, sense of security, and fulfillment of lifetime aspirations (Peterson, Ekici, \& Hunt, 2010). Remuneration is also linked to employees' views of how their efforts benefit their employers, and how important their contribution is when compared with that of others, which is relevant to the fairness of remuneration policies (Gerhart \& Rynes, 2003). The mixed concerns of adequacy and fairness of remuneration usually critically challenge organizations to manage employees with different expectations of living standards (Hofmans, De Gieter, \& Pepermans, 2013). Research also suggests that remuneration can influence performance through two different mechanisms, i.e., the incentive-outcome effect, and the sorting effect (Gerhart, 2004; Gerhart \& Fang, 2014). The incentive-outcome effect considers the motivational impact of remuneration upon individual employee performance. The rationale behind doing so is that remuneration is a factor in motivating employees. In contrast, the sorting effect concerns the influence of remuneration on the type of employees that are attracted to, or retained by, organizations. It is grounded in the belief that remuneration helps attract and retain those whose work attributes and performance are appropriate for employers. Accordingly, it is crucial that employees should perceive a congruence between their remuneration, and what they desire to acquire in their work and life domains; there is much research highlighting the relationship between satisfaction with remuneration and both personal economic wellbeing and physical and psychological wellbeing (Kessler, 2013).

\subsubsection{Workplace diversity and inclusion}

In the organizational literature, diversity describes the composition of groups or workforces. Workplace diversity refers to characteristics such as gender, race, ethnicity, age, class, sexual orientation and cultural attributes of employees (Kochan et al., 2003; Jayne \& Dipboye, 2004; Lau \& Murnighan, 2005). The concept of inclusion would imply no discrimination against workers owing to any of these characteristics, so that they feel satisfactorily integrated into their work team, and the organization in general. Similar to other scholars in the field, Jayne and Dipboye (2004, p. 410) advocate that "inclusion as a diversity strategy attempts to embrace and leverage all employee differences to benefit the organization. As a result, managing all workers well has become the focus of many corporate diversity initiatives."

Nowadays there are many organizations, particularly those operating internationally, that manage a large number of interdependent functional work tasks, employing diverse professionals and operational employees as networked, complementary resources (Driedonks et al., 2010; Ng \& Wyrick, 2011; Van Knippenberg, van Ginkel, \& Homan, 2013). There are many studies examining different aspects of workplace diversity — cultural, ethnic, age, religion - and their influence on wellbeing (e.g., Enchautegui-de-Jesús, Hughes, Johnston, \& Oh, 2006; Pettersson, 2006). In social theories, the presence of group dominance impedes organizations or institutions from tapping into the full potential arising from their workers' different attributes (Jayne \& Dipboye, 2004; Gutiérrez \& Saint Clair, 2018). Coordinated or collaborative workforce diversity encourages organizations to move towards new business orientations and innovations (To, 2016). Diversity and the acceptance of differences in the workplace can catalyze organizational culture changes that win the trust of all the stakeholders in the entire business and social 
ecosphere (Mamman, Kamoche, \& Bakuwa, 2012). As such, workforce diversity and inclusion provide a means to nurture a work culture infused with cooperate goodwill, and employees who value their workplace identity (Mamman et al., 2012).

After reviewing the literature on the topics of interest, we could posit one main effect of each of the quality of working life factors on each of the individual's wellbeing domains. At first sight, it would appear that all the quality of working life factors should be positively perceived for employee to perceive wellbeing. However, this could be a consequence of the methodology commonly used, which is mainly based on dependency or causal relationships. FsQCA considers equifinality and causal complexity tenets and, accordingly, this research attempts to answer the following research question:

RQ1: Which of these attributes of the quality of working life, i.e. the employee's perception of a) workplace conditions, b) working life autonomy, c) corporate citizenship, d) remuneration, and e) workplace diversity and inclusion, are necessary to perceive wellbeing in each of the three areas analyzed, i.e. (i) perception of work-life balance, (ii) career opportunities, and (iii) health and wellness?

RQ2: How should the attributes of quality of working life under consideration be combined to ensure wellbeing in each of the three areas analyzed?

\section{Methodology}

\subsection{Context of the analysis}

This research conducted an empirical survey of international companies in the estuary of the Pearl River Delta (PRD) region of Southern China. The PRD is the context of this study for two reasons. First, worklife vulnerability is an imperative concern for companies in the PRD. The economic drivers of this region are mainly based on international trade and industrial services, with an export value of approximately US\$646 billion in 2018 (National Bureau of Statistics of China, 2019), making up $26 \%$ of China's total exports by value. The massive industrial and service sectors create tremendous social and environmental challenges to companies in areas such as social security and identity as well as health and pollution, leading to management concerns about work-life vulnerabilities (Locke \& Romis, 2007; Valentine et al., 2011). Second, the efficacy of workforce maintenance management is a key performance indicator of companies in the PRD, where, workload, work dignity, and psychological stress have been the subject of much criticism (Lucas et al., 2013). For management, their employees' working life is not merely a managerial matter, involving such concerns as where people in the workplace are located, or how much time employees can rest, but a strategic issue that involves mitigating foreseeable workforce vulnerabilities. As such, companies should assess their performance by looking at the wellness of their employees, and the efficacy of workforce maintenance management. For these reasons, the PRD region is a suitable context in which issues of work-life management and individual wellbeing are examined.

\subsection{Data collection}

To answer the proposed research questions, we conducted quantitative research, gathering information through an online structured questionnaire. The questionnaire was divided into two main parts. The first part was concerned with the socio-demographic variables of the interviewees, while the second part focused on measuring the main constructs of analysis. The scales to measure those constructs were based on considerations posited in existing literature on the topic and on scales previously used, but adapted to the context of the present research. Workplace conditions were measured considering the suggestions made in the research of Maher and von Hippel (2005), Kim and Dear (2013), Kossek (2016), and Moskaliuk, Burmeister, Landkammer, Renner, and Cress (2017); working life autonomy, using suggestions from Grzywacz and Marks (2000), Kossek et al. (2014), and Prem et al. (2016); corporate citizenship, from Edwards and Rothbard (2000), Podsakoff et al. (2000), Hanson et al. (2006), and Hammond et al. (2017); remuneration, from Gerhart and Rynes (2003), Hofmans et al. (2013), and Gerhart and Fang (2014); workplace diversity and inclusion, from Jayne and Dipboye (2004), Ng and Wyrick (2011), Mamman et al. (2012), and Gutiérrez and Saint Clair (2018), and; work-life balance, from Hill et al. (2001) and Greenhaus, Collins, and Shaw (2003); working life opportunities, from Ilies and Judge (2003) and Creed et al. (2017); and health and wellness, from Baicker at al. (2010), Indumathy (2012) and Hoert et al. (2018). Respondents judged all these aspects of working conditions on five-point multi-item Likert scales, ranging from 1: "completely disagree"; to 5: "completely agree".

This questionnaire was targeted at executives working in international companies, including those in international multi-merchandise stores, associates of buying agents, coordinators in multinational manufacturing corporations, and consultants working for international audit firms. To participate in the survey, respondents had to meet two criteria. One was that they should be knowledgeable of the specific working life characteristics of their organization, by either experience or qualification. Meeting this criterion should show that respondents can appropriately comment on work-life management interventions in the areas of interest. The other criterion was that they should be able to state their career aspirations and personal life orientation. This criterion ensured that the responses would substantially and sufficiently reflect the possible relationship between work-life experience and perceived wellbeing.

Convenience sampling was used. Upon completion of data collection, 176 questionnaires were gathered. However, eleven questionnaires were incomplete and discarded. A total of 165 responses were therefore subjected to further analysis.

\subsection{Psychometric properties of the scales}

Before analyzing the data to answer the research questions, we assessed the psychometric properties of the scales (Table 1). The confirmatory factor analysis, performed with Partial Least Squares, showed that it was not necessary to eliminate any item from any of the scales, as the standardized loadings on their respective factors were significant and greater than 0.6 (Bagozzi \& Yi, 1988). As Table 1 displays, all scales met the criteria for reliability, convergent, and discriminant validity. Cronbach's alphas showed values higher than 0.7 (Nunnally \& Bernstein, 1994); composite reliability showed values above the suggested minimum threshold of 0.8 (Bagozzi \& Yi, 1988); the average variance extracted values were greater than the accepted threshold of 0.5 , and the covariances between constructs were lower than the corresponding average variance extracted, ensuring discriminant validity (Fornell \& Larcker, 1981).

\subsection{Analysis method: fsQCA}

This study employs the fsQCA method to analyze the collected data. The distinctive feature of the fsQCA method is that it identifies and analyzes combinations of causal conditions that lead to a particular outcome. The identification and analysis reveal the interconnected structures of the causes in various configurations, and the complex nature of the interdependencies between causes, in each configuration (Ragin, 2000, 2008). It is not based on symmetric relationships among variables, and it is expected that the causal structure will be equifinal and complex (Woodside, 2016). Considering that the main goal of this study is to identify the configurative structures of the quality of working life factors, and to analyze the configurations' impacts on the three employees' wellbeing domains, fsQCA is an appropriate method. It offers a detailed understanding of the complex causal relationships between the quality of working life factors and wellbeing, as well as rich insights into the effect of causal recipes of wellbeing. 
Table 1

Psychometric properties of the scales.

\begin{tabular}{|c|c|c|c|c|c|c|c|c|c|c|c|}
\hline \multicolumn{4}{|c|}{ Reliability and convergent validity } & \multicolumn{8}{|c|}{ Discriminant validity } \\
\hline AVE & CR & Cronb & & WPC & WLA & $\mathrm{CC}$ & $\mathrm{R}$ & DI & WLB & WLO & HW \\
\hline 0.715 & 0.909 & 0.866 & WPC & 0.845 & & & & & & & \\
\hline 0.714 & 0.909 & 0.865 & WLA & 0.816 & 0.845 & & & & & & \\
\hline 0.682 & 0.915 & 0.882 & CC & 0.790 & 0.774 & 0.826 & & & & & \\
\hline 0.701 & 0.903 & 0.854 & $\mathrm{R}$ & 0.431 & 0.509 & 0.511 & 0.837 & & & & \\
\hline 0.772 & 0.931 & 0.901 & DI & 0.817 & 0.833 & 0.786 & 0.402 & 0.878 & & & \\
\hline 0.831 & 0.936 & 0.899 & WLB & 0.391 & 0.377 & 0.374 & 0.417 & 0.356 & 0.911 & & \\
\hline 0.607 & 0.857 & 0.782 & WLO & 0.391 & 0.377 & 0.374 & 0.417 & 0.356 & 0.309 & 0.779 & \\
\hline 0.548 & 0.846 & 0.728 & HW & 0.750 & 0.651 & 0.698 & 0.368 & 0.671 & 0.469 & 0.509 & 0.805 \\
\hline
\end{tabular}

Note: Correlations between constructs appear below the diagonal; the square root of the average variance extracted (AVE) appears on the diagonal.

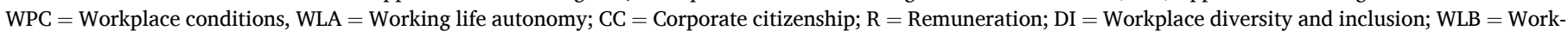
life balance; WLO = Working life opportunities; HW = Health and wellness;

$\mathrm{AVE}=$ Average Variance Extracted; $\mathrm{CR}=$ Composite Reliability

FsQCA treats all of the measurements from each respondent as an individual case and calibrates the raw item measurements (measure on a five-point Likert interval scale) into fuzzy membership scores within a 0 to 1 range. This means that each multi-item scale has to be transformed into one single-item scale in order to be calibrated. With that purpose, we calculated the average of each multi-item scale. To transform each variable (or one single-item scale) into calibrated sets, we set three thresholds: full membership (1), full non-membership (0), and crossover point (i.e., the point of maximum ambiguity, -0.5) (Ragin, 2008). The values considered for calibration were 5 for full membership, 1 for full non-membership and 3 for the cross-over point.

\section{Results}

In order to answer RQ1, following Ragin's (2000, 2008) guideline, we tested the necessary conditions for each outcome to occur; i.e., whether each causal condition was needed for perceiving work-life balance, working life opportunities, and health and wellness. The thresholds used to check the necessity were 0.90 for consistency, and 0.75 for coverage (Ragin, 2006). Table 2 displays the results. We find that not all the five causal conditions play the same role in bringing about the three outcomes. Regarding the perception of work-life balance, only perception of working life autonomy, and satisfaction with workplace diversity and inclusion, are necessary conditions for it to occur. Nevertheless, when considering perception of working life opportunities, four out of the five causal conditions are necessary; results show that satisfaction with remuneration is the only causal condition that is not necessary for an employee to perceive working life opportunities. Finally, for the individual to perceive health and wellness, no causal condition is necessary, as none of the variables considered meets the required thresholds.

We checked the sufficient conditions in order to answer RQ2. FsQCA models the solutions (i.e., the configurations of the five quality of working life factors) that sufficiently precondition the three wellbeing outcomes, i.e., perception of work-life balance, of working life opportunities, and of health and wellness. The five causal conditions-workplace conditions, working life autonomy, corporate citizenship, remuneration, and workplace diversity and inclusion-must be the supersets of these three outcomes.

When performing this analysis, it is necessary to consider that, in the fsQCA, not every theoretic configuration occurs in the observations, or at appreciable occurrence rates. Therefore, proportional reduction in inconsistency (PRI) was conducted to test possible hidden asymmetry, in which both the presence and absence of the considered causal conditions could result in the solutions with valid, sufficient consistency. Such contradictory asymmetry would violate the logicality and causality of the interpretation. Those configurations with PRI consistency values below the theoretic threshold of 0.5 are considered to be violating the logical set-theoretic relations; hence, they must be removed from the truth table before any further solution analysis. In fsQCA, membership scores of outcomes should be consistently greater than the scores of configured conditions of antecedents. Ragin (2008) formalized the value of consistency necessary to indicate the extent to which a subset relationship can be verified reliably or proximately. This research sets the minimum threshold of raw consistency at 0.8 to test the set-theoretic relationships. Moreover, the fsQCA conservatively sets the minimum frequency cut-off at two, when specifying the observed cases for analysis (Ragin, 1994, 2008). All these considerations were applied to the analysis of the sufficient conditions. Table 3 summarizes the results of the immediate solutions for each outcome.

For $86 \%$ of those interviewed who perceived work-life balance, that perception of work-life balance can be explained by one of the four causal configurations (solutions) depicted in Table 3; the overall consistency, a comparable value to the R-squared (Woodside, 2013), is 0.91 which indicates the extent to which perceiving work-life balance can be related to a set of configurations. Accordingly, employees who perceive work-life balance: (1) are satisfied with their workplace conditions, perceive high working life autonomy, perceive corporate citizenship, and also high workplace diversity and inclusion; (2) are satisfied with their workplace conditions, perceive high working life autonomy, perceive corporate citizenship, and are satisfied with their remuneration; (3) are satisfied with their remuneration, but do not perceive working life autonomy, nor corporate citizenship, nor workplace diversity and inclusion; (4) perceive corporate citizenship, but are not

Table 2

Necessary conditions for the outcomes to occur.

\begin{tabular}{|c|c|c|c|c|c|c|}
\hline & \multicolumn{2}{|c|}{ Perception of work-life balance } & \multicolumn{2}{|c|}{ Perception of working life opportunities } & \multicolumn{2}{|c|}{ Perception of health and wellness } \\
\hline & consistency & coverage & consistency & coverage & consistency & coverage \\
\hline Satisfaction with workplace conditions & 0.89 & 0.86 & 0.91 & 0.91 & 0.86 & 0.96 \\
\hline Perception of working life autonomy & 0.90 & 0.88 & 0.92 & 0.93 & 0.85 & 0.95 \\
\hline Perception of corporate citizenship & 0.89 & 0.89 & 0.92 & 0.94 & 0.84 & 0.96 \\
\hline Satisfaction with remuneration & 0.87 & 0.91 & 0.88 & 0.94 & 0.80 & 0.95 \\
\hline Perception of workplace diversity and inclusion & 0.91 & 0.85 & 0.93 & 0.89 & 0.87 & 0.94 \\
\hline
\end{tabular}

Note: The conditions identified as necessary are in bold. 
Table 3

Sufficient conditions for the outcomes to occur.

\begin{tabular}{|c|c|c|c|c|c|c|c|c|c|}
\hline \multirow[t]{2}{*}{ Drivers } & \multicolumn{4}{|c|}{ Perception of work-life balance } & \multicolumn{4}{|c|}{ Perception of working life opportunities } & \multirow{2}{*}{$\begin{array}{l}\text { Perception of health and wellness } \\
\text { Sol.1 }\end{array}$} \\
\hline & Sol.1 & Sol.2 & Sol.3 & Sol.4 & Sol.1 & Sol.2 & Sol.3 & Sol.4 & \\
\hline Satisfaction with workplace conditions & $\bullet$ & $\bullet$ & & $\varnothing$ & $\bullet$ & $\bullet$ & & $\varnothing$ & $\bullet$ \\
\hline Perception of working life autonomy & $\bullet$ & $\bullet$ & $\varnothing$ & $\varnothing$ & $\bullet$ & $\bullet$ & $\varnothing$ & $\varnothing$ & $\bullet$ \\
\hline Perception of corporate citizenship & $\bullet$ & $\bullet$ & $\varnothing$ & $\bullet$ & $\bullet$ & $\bullet$ & $\varnothing$ & $\bullet$ & $\bullet$ \\
\hline Satisfaction with remuneration & & $\bullet$ & • & & & $\bullet$ & • & & \\
\hline Perception of workplace diversity and inclusion & $\bullet$ & & $\varnothing$ & $\varnothing$ & $\bullet$ & & $\varnothing$ & $\varnothing$ & $\bullet$ \\
\hline Raw Coverage & 0.81 & 0.81 & 0.60 & 0.58 & 0.85 & 0.86 & 0.60 & 0.60 & 0.91 \\
\hline Unique coverage & 0.02 & 0.01 & 0.10 & 0.10 & 0.02 & 0.01 & 0.01 & 0.01 & 0.91 \\
\hline Consistency & 0.94 & 0.94 & 0.96 & 0.72 & 0.97 & 0.97 & 0.97 & 0.98 & 0.92 \\
\hline Overall solution coverage & 0.86 & & & & 0.91 & & & & 0.91 \\
\hline Overall solution consistency & 0.91 & & & & 0.94 & & & & 0.92 \\
\hline Frequency cut off & 2 & & & & 2 & & & & 2 \\
\hline Consistency cut off & 0.94 & & & & 0.97 & & & & 0.93 \\
\hline
\end{tabular}

Note: indicates the presence of a condition; $\varnothing$ indicates its absence; blank space indicates "don't care".

satisfied with workplace conditions, nor do they perceive working life autonomy, nor workplace diversity and inclusion. The first two causal configurations are the ones that encompass most of the employees perceiving work-life balance.

Concerning the results for the perception of working life opportunities, according to Table 3 , we can see that the four solutions, considered altogether, can explain $91 \%$ of the cases reporting employees' high perception of working life opportunities. It is surprising that the four causal configurations resulting in sufficient conditions for this outcome to occur are the same as those for the perception of work-life balance; also, the two first-mentioned causal configurations are, again, the ones that encompass most of the employees with a high perception of working life opportunities.

Finally, only one causal configuration is found to be a sufficient condition for employees perceiving health and wellness; this causal configuration accounts for $91 \%$ of the employees reporting high health and wellness perception. An employee reporting perception of health and wellness is an employee who is satisfied with his or her workplace conditions, perceives high working life autonomy, perceives corporate citizenship, and a high degree of workplace diversity and inclusion. This solution is also a sufficient causal configuration for the other two outcomes to occur. Remarkably, satisfaction with remuneration is not a causal condition leading to perception of health and wellness.

From these results, we demonstrate that working life autonomy and corporate citizenship are key issues in influencing perception of worklife balance, of working life opportunities and of health and wellness, as these two causal conditions, present or absent, are in all the causal configurations reported for the analyzed outcomes. We also consider it relevant to mention that remuneration, when it does play a role within a causal configuration in the perception of work-life balance and of working life opportunities, has to be present (not absent); i.e., the individual has to be satisfied with it in order to participate in reaching the outcomes.

\section{Discussion and conclusions}

Driven by the ever-increasing demands of the work environment, the quality of working life is recognized as vital for the wellbeing of the workforce in contemporary organizational contexts (Grote \& Guest, 2017). The individual's working life and personal sphere are inextricably linked, and there are many aspects of the working life context that can have consequences at a personal and/or family level. These connections will have a significant impact on individuals' wellbeing and, consequently, their overall job satisfaction and whether they intend to stay or leave their place of work.

This research considers some factors that make up the quality of working life, and identifies the role of various set-theoretic configurations of these factors in favoring specific domains of the individual's wellbeing, linked with effective workforce maintenance. The analyzed factors of quality of the working life comprise satisfaction with workplace conditions, perception of working life autonomy, perception of corporate citizenship, satisfaction with remuneration, and perception of workplace diversity and inclusion; the wellbeing outcomes comprise perception of work-life balance, working life opportunities, and health and wellness.

The paper contributes to a clearer understanding of which factors related to the quality of working life are present when the individual feels wellbeing, both within and outside the workplace. Such wellbeing improves the commitment of the workforce to their workplace. Furthermore, this study reveals that the key conditions of work-life wellness are attainable in today's globalized businesses. It also recognizes the need for, and the importance of, fsQCA in understanding contextual relationships in business management.

The answers to the two research questions lead to two main conclusions. The first is that the quality of working life factors considered here are not equally necessary for the individual to perceive wellbeing in the three analyzed domains. In fact, for the health and wellness domain, no causal condition is necessary; however, the working life opportunities domain appears at the other extreme, as four out of the five factors are necessary (only remuneration plays no role).

The second conclusion is that the same combination of quality of working life factors results in sufficient conditions for the three outcomes. Accordingly, managers can practice the same interventions with respect to these factors to achieve different results for wellbeing. In fact, of the different quality of working life factors, two play a key role: the perception of corporate citizenship and remuneration.

The perception of corporate citizenship appears in all the solutions, being present in three solutions and absent in one. The presence of corporate citizenship leads to the perception of work-life balance and working life opportunities even in the absence of other causal conditions. Moreover, it is a necessary condition for the perception of working life opportunities. These results show that corporate citizenship exerts a supporting effect on the three domains of the individual's wellbeing. Management should therefore not ignore the fact that corporate citizenship can benefit employees in all these ways. Employees are more likely to perceive work-life balance, working life opportunities, and health and wellbeing when their organization cultivates its reputation as a good corporate citizen. As well as boosting employees' wellbeing, it makes a positive contribution to the society, and its values permeate the entire organization. Most of the research on corporate citizenship has looked into its influence on external stakeholders (Maignan \& Ferrell, 2001b); yet, it can be seen that it significantly impacts the internal stakeholders; that is, the employees. Workers not only can observe how their company's policies and practices affect their local community or society in general, but also can directly benefit from their company's corporate citizenship through better wages, or better working life 
practices regarding health, safety or other working conditions (Rego et al., 2010); consequently, that perception of corporate citizenship influences their affective commitment to their organization (Peterson, 2004; Rego et al., 2010). Literature suggests a positive link between perceived corporate citizenship and the expectations of career success of those seeking jobs (Lin et al., 2012). In addition, research highlights that the employee's perception of receiving social support within the company is even more important to better working life outcomes than the formal presence of family-friendly policies (Allen, 2001; Thompson \& Prottas, 2006). These results could explain why, even in the absence of satisfaction with workplace conditions and of perception of working life autonomy and workplace diversity and inclusion, employees perceive work-life balance and working life opportunities when they perceive corporate citizenship.

Focusing on remuneration, the present research brings together two research perspectives on job satisfaction and turnover intention, with ambiguous theoretical and empirical results. As Nyberg (2010) highlights, some studies analyzing employees' decisions as to whether to remain in or leave an organization focus on the individual's attitude, and do not consider remuneration. This stream of research provides support to the solution in which four out of the five causal conditions analyzed have to be present for employees to perceive work-life balance and working life opportunities, namely: satisfaction with workplace, perception of autonomy, corporate citizenship, and workplace diversity and inclusion. However, Nyberg (2010) suggests a negative relationship between employee performance and voluntary turnover, in which job satisfaction plays no role. Our findings reveal that, even when individuals do not perceive quality in their working life (more precisely, they do not perceive working life autonomy, corporate citizenship, or workplace diversity and inclusion), when they are satisfied with their remuneration they have a positive perception of work-life balance as well as of working life opportunities. Thus, for some employees, high satisfaction with remuneration can compensate for their low satisfaction with regard to some aspects of quality of working life, resulting in a perception of wellbeing in terms of work-life balance and working life opportunities. These results give support to Wilensky (1960) proposition that individual can seek reward in one domain to compensate for dissatisfaction in other domains; and also for the spillover hypothesis, that what happens in one individual's domain has consequences in his or her other domains.

On the other hand, perception of health and wellness is not found to have the relationship with remuneration that one would reasonably expect; yet, it is linked to workplace and job characteristics (conditions and autonomy), diversity and inclusion, and how workers perceive their organization's corporate citizenship.

For employees to perceive wellbeing, satisfactory workplace conditions and working life autonomy have to be present, except when they are satisfied with remuneration or perceive corporate citizenship. To put it another way, in the latter two situations, satisfactory workplace conditions and working life autonomy can be absent for employees to perceive wellbeing.

Surprisingly, the individual can perceive wellbeing even in the absence of perception of workplace diversity and inclusion. Perhaps, this picture reflects the "one-size-fits-all" policies of diversity and inclusion suggested by Hutchinson (2018), i.e. when managers believe that a single policy fits everybody. Quite often, supervisors have an unconscious bias when giving support to employees' requests that contain reasons motivated by diversity interests; they are prone to deny requests that they do not understand, or find meaningless (Hutchinson, 2018).

To summarize, we conclude that the quality of an individual's working life is influenced by his or her satisfaction with workplace conditions, perception of autonomy, corporate citizenship and workplace diversity, as well as satisfaction with remuneration: all are important elements for that can contribute to the individual's wellbeing in terms of work-life balance, working life opportunities, and health and wellness. Nevertheless, managers do not have to consider all of them together, nor the presence of any single factor. Instead, it is important that they consider how some or all of these factors combine.

The results of this study suggest some ways in which managers can intervene that improve the quality of working life of their employees. Since not all employees have the same vision of wellbeing, such interventions could be tailored according to the specific situation and characteristic of the employee. This would involve an additional effort by managers to find out what exactly influences the wellbeing of each employee. Whatever the case, management would be well advised to accommodate the mutuality between economic and social considerations in order to reduce employee turnover.

Management may decide to rely solely on monetary compensation to foster their employees' wellbeing. However, this might be effective only for those employees who perceive money as the most important reward for their work. These employees would consider a higher monetary reward as compensation for those other aspects of the quality of their working life with which they are not satisfied.

Regarding social considerations, management wanting to maintain a loyal workforce would do well to consider their employees' satisfaction with workplace conditions, with their working life autonomy, the company's corporate citizenship, and workplace diversity and inclusion. Employees more readily perceive workplace conditions and work-life autonomy, than corporate citizenship and workplace diversity and inclusion. To promote corporate citizenship, companies should communicate properly and through the appropriate media about their actions linked to corporate citizenship. This would enable employees to perceive how committed their companies are to them and to wider society. Managers should show that they see workplace diversity and inclusion as imperative for their companies and intervene appropriately. They could make an effort to analyze all the diversity categories existing in the organization, or establish a diversified advisory team in order to enhance supervisors' awareness of diversity in their organization.

As with other studies, this research has certain limitations. It focuses on the limited geographical area in which data were collected. Future research should be conducted in other geographical areas to establish whether the results of this study can be generalized. Although literature supports the relationship between the outcomes analyzed in this paper and employees' intentions as to whether or not to remain with their company, this paper does not measure such intentions; future research should consider doing so, to enrich the understanding of workforce maintenance.

Moreover, future papers should focus on the influence of working life attributes in other wellbeing domains, mainly that of employees' personal life outside the work environment. One interesting factor that could be explored in future analysis is the employee's gender; literature suggests that the role and the perception of work-life balance and career opportunities are perceived differently according to gender. Likewise, it would be interesting to use other methodologies, with the same variables, to compare results and strengthen theoretical knowledge of this topic.

\section{Acknowledgements}

This work was partially supported by grants from The Hong Kong Polytechnic University under grant numbers 4-ZZGL and G-YBVA. We also thank Dr Chester To at the Hong Kong Polytechnic University for his insightful comments on this work.

\section{References}

Alisic, A., \& Wiese, B. S. (2020). Keeping an insecure career under control: The longitudinal interplay of career insecurity, self-management, and self-efficacy. Journal of Vocational Behavior, 120(August), 1034-1131.

Allen, T. D. (2001). Family-supportive work environments: The role of organizational perceptions. Journal of Vocational Behavior, 58(3), 414-435.

Bagozzi, R. P., \& Yi, Y. (1988). On the evaluation of structural equation models. Journal of the Academy of Marketing Science, 16(1), 74-94. 
Baicker, K., Cutler, D., \& Song, Z. (2010). Workplace wellness programs can generate savings. Health Affairs, 29(2), 304-311.

Benavides, F. G., Benach, J., Muntaner, C., Delclos, G. L., Catot, N., \& Amable, M. (2006). Associations between temporary employment and occupational injury: What are the mechanisms? Occupational and Environmental Medicine, 63(6), 416-421.

Böhnke, P., \& Cifuentes, I. V. (2018). Employment patterns and family satisfaction in Europe. International Journal of Sociology and Social Policy, 38(5-6), 394-410.

Burton, J. (2010). WHO healthy workplace framework and model: Background and supporting literature and practices. Geneva, Switzerland: World Health Organization.

Carlson, D. S., Thompson, M. J., \& Kacmar, K. M. (2019). Double crossed: The spillover and crossover effects of work demands on work outcomes through the family. Journal of Applied Psychology, 104(2), 214-228.

Creed, P. A., Hood, M., \& Hu, S. (2017). Personal orientation as an antecedent to career stress and employability confidence: The intervening roles of career goalperformance discrepancy and career goal importance. Journal of Vocational Behavior, 99, 79-92.

Cummins, R. A. (2005). Caregivers as managers of subjective wellbeing: A homeostatic perspective. Journal of Applied Research in Intellectual Disabilities, 18(4), 335-344.

Daud, N. (2010). Investigating the relationship between quality of work life and organizational commitment amongst employees in Malaysian firms. International Journal of Business and Management, 5(10), 75-82.

Delanoeije, J., Verbruggen, M., \& Germeys, L. (2019). Boundary role transitions: A dayto-day approach to explain the effects of home-based telework on work-to-home conflict and home-to-work conflict. Human Relations, 72(12), 1843-1868.

Driedonks, B. A., Gevers, J. M. P., \& van Weele, A. J. (2010). Managing sourcing team effectiveness: The need for a team perspective in purchasing organizations. Journal of Purchasing and Supply Management, 16(2), 109-117.

Dumas, T. L., \& Sanchez-Burks, J. (2015). The professional, the personal and the ideal worker: Pressures and objectives shaping the boundary between life domains. The Academy of Management Annals, 9(1), 803-843.

Edwards, J. R., \& Rothbard, N. P. (2000). Mechanisms linking work and family: Clarifying the relationship between work and family constructs. The Academy of Management Review, 25(1), 178-199.

Enchautegui-de-Jesús, N., Hughes, D., Johnston, K. E., \& Oh, H. J. (2006). Wellbeing in the context of workplace ethnic diversity. Journal of Community Psychology, 34(2), 211-223.

Eurofound. (2015). New Forms of Employment. Luxembourg: Publications Office of the European Union.

Fornell, C., \& Larcker, D. F. (1981). Evaluating structural equation models with unobservable variables and measurement error. Journal of Marketing Research, 18(1), 39-50.

Gerhart, B. (2004). Comment: "Promise and peril in implementing pay-for-performance", by Michael Beer and Mark D. Cannon. Human Resource Management, 43(1), 29-31.

Gerhart, B., \& Fang, M. (2014). Pay for (individual) performance: Issues, claims, evidence and the role of sorting effects. Human Resource Management Review, 24(1), 41-52.

Gerhart, B., \& Rynes, S. (2003). Compensation: Theory, evidence, and strategic implications. Thousand Oaks, CA: SAGE Publications.

Greenhaus, J. H., Collins, K. M., \& Shaw, J. D. (2003). The relation between work-family balance and quality of life. Journal of Vocational Behavior, 63(3), 510-531.

Grote, G., \& Guest, D. (2017). The case for reinvigorating quality of working life research. Human Relations, 70(2), 149-167.

Grzywacz, J. G., \& Marks, N. F. (2000). Reconceptualizing the work-family interface: An ecological perspective on the correlates of positive and negative spillover between work and family. Journal of Occupational Health Psychology, 5(1), 111-126.

Guest, D. E. (2002). Perspectives on the study of work-life balance. Social Science Information, 41(2), 255-279.

Gutiérrez, A. S., \& Saint Clair, J. K. (2018). Do organizations' diversity signals threaten members of the majority group? The case of employee professional networks. Journal of Business Research, 89, 110-120.

Haar, J. M., Russo, M., Suñe, A., \& Ollier-Malaterre, A. (2014). Outcomes of work-life Balance on job satisfaction, life satisfaction and mental health: A study across seven cultures. Journal of Vocational Behavior, 85(3), 361-373.

Hammond, M., Clapp-Smith, R., \& Palanski, M. (2017). Beyond (just) the workplace a theory of leader development across multiple domains. Academy of Management Review, 42(3), 481-498.

Hanson, G. C., Hammer, L. B., \& Colton, C. L. (2006). Development and validation of a multidimensional scale of perceived work-family positive spillover. Journal of Occupational Health Psychology, 11(3), 249-265.

Hill, E. J., Hawkins, A. J., Ferris, M., \& Weitzman, M. (2001). Finding an extra day a week: The positive influence of perceived job flexibility on work and family life balance. Family Relations, 50(1), 49-58.

Hoert, J., Herd, A., \& Hambrick, M. (2018). The role of leadership support for health promotion in employee wellness program participation, perceived job stress, and health behaviors. American Journal of Health Promotion, 32(4), 1054-1061.

Hofmans, J., De Gieter, S., \& Pepermans, R. (2013). Individual differences in the relationship between satisfaction with job rewards and job satisfaction. Journal of Vocational Behavior, 82(1), 1-9.

Hutchinson, D. (2018). Work-life balance in the workplace. In Diversity and Inclusion in the Global Workplace (pp. 185-200). Cham: Palgrave Macmillan.

Iachini, T., Coello, Y., Frassinetti, F., Senese, V. P., Galante, F., \& Ruggiero, G. (2016). Peripersonal and interpersonal space in virtual and real environments: Effects of gender and age. Journal of Environmental Psychology, 45, 154-164.

Ilies, R., \& Judge, T. A. (2003). On the heritability of job satisfaction: The mediating role of personality. Journal of Applied Psychology, 88(4), 750-759.
Indumathy, R. (2012). A study on quality of work life among workers with special reference to textile industry in Tirupur district - A textile hub. Journal of Contemporary Management Research, 6(1), 78-90.

Jayne, M. E. A., \& Dipboye, R. L. (2004). Leveraging diversity to improve business performance: Research findings and recommendations for organizations. Human Resource Management, 43(4), 409-424.

Kessler, I. (2013). Remuneration systems. In Stephen Bach, \& Martin R. Edwards (Eds.), Managing human resources: Human resource management in transition (pp. 243-267). West Sussex: John Wiley \& Sons Ltd.

Kim, J., \& de Dear, R. (2013). Workspace satisfaction: The privacy-communication tradeoff in open-plan offices. Journal of Environmental Psychology, 36, 18-26.

Kim, S. Y., Fouad, N., \& Lee, J. (2018). The roles of work and family in men's lives: Testing the social cognitive model of career self-management. Journal of Vocational Behavior, 106, 153-164.

Kochan, T., Bezrukova, K., Ely, R., Jackson, S., Joshi, A., Jehn, K., ... Thomas, D. (2003). The effects of diversity on business performance: Report of the diversity research network. Human Resource Management, 42(1), 3-21.

Korunka, C., Hoonakker, P., \& Carayon, P. (2008). Quality of working life and turnover intention in information technology work. Human Factors and Ergonomics in Manufacturing and Service Industries, 19(4), 409-423.

Kossek, E. E. (2016). Managing work-life boundaries in the digital age. Organizational Dynamics, 45(3), 258-270.

Kossek, E. E., Hammer, L. B., Kelly, E. L., \& Moen, P. (2014). Designing work, family \& health organizational change initiatives. Organizational Dynamics, 43(1), 53-63.

Kossek, E. E., Ruderman, M. N., Braddy, P. W., \& Hannum, K. M. (2012). Work-nonwork boundary management profiles: A person-centered approach. Journal of Vocational Behavior, 81(1), 112-128.

Lau, A. L. D., Cummins, R. A., \& McPherson, W. (2005). An investigation into the crosscultural equivalence of the Personal Wellbeing Index. Social Indicators Research, 72 (3), 403-430.

Lau, D. C., \& Murnighan, J. K. (2005). Interactions within groups and subgroups: The effects of demographic faultiness. Academy of Management Journal, 48(4), 645-659.

Lin, C. P., Tsai, Y. H., Joe, S. W., \& Chiu, C. K. (2012). Modeling the relationship among perceived corporate citizenship, firms' attractiveness, and career success expectation. Journal of Business Ethics, 105(1), 83-93.

Locke, R., \& Romis, M. (2007). Improving work conditions in a global supply chain. MIT Sloan Management Review, 48(2), 54-62.

Lucas, K., Kang, D., \& Li, Z. (2013). Workplace dignity in a total institution: Examining the experiences of Foxconn's migrant workforce. Journal of Business Ethics, 114(1), 91-106.

Lucas, K., Manikas, A. S., Mattingly, E. S., \& Crider, C. J. (2017). Engaging and misbehaving: How dignity affects employee work behaviors. Organization Studies, 38 (11), 1505-1527.

Maher, A., \& von Hippel, C. (2005). Individual differences in employee reactions to openplan offices. Journal of Environmental Psychology, 25(2), 219-229.

Maignan, I., \& Ferrell, O. C. (2001a). Antecedents and benefits of corporate citizenship: An investigation of French businesses. Journal of Business Research, 51(1), 37-51.

Maignan, I., \& Ferrell, O. C. (2001b). Corporate citizenship as a marketing instrument: Concepts, evidence and research directions. European Journal of Marketing, 35(3/4), $457-484$.

Makarius, E. E., \& Larson, B. Z. (2017). Changing the perspective of virtual work: Building virtual intelligence at the individual level. Academy of Management Perspectives, 31(2), 159-178.

Mamman, A., Kamoche, K., \& Bakuwa, R. (2012). Diversity, organizational commitment and organizational citizenship behavior: An organizing framework. Human Resource Management Review, 22(4), 285-302.

May, B. E., Lau, R. S. M., \& Johnson, S. K. (1999). A longitudinal study of quality of work life and business performance. South Dakota Business Review, 58(2), 3-7.

Mickel, A. E., \& Dallimore, E. J. (2009). Life-quality decisions: Tension-management strategies used by individuals when making tradeoffs. Human Relations, 62(5), 627-668.

Mosadeghrad, A. M. (2013). Quality of working life: An antecedent to employee turnover intention. International Journal of Health Policy and Management, 1(1), 43.

Moskaliuk, J., Burmeister, C. P., Landkammer, F., Renner, B., \& Cress, U. (2017). Environmental effects on cognition and decision making of knowledge workers. Journal of Environmental Psychology, 49(1), 43-54.

Napolitano, C. M., Hoff, K. A., Ming, C. W. J., Tu, N., \& Rounds, J. (2020). Great expectations: Adolescents' intentional self-regulation predicts career aspiration and expectation consistency. Journal of Vocational Behavior, 120(August), 1034-1123.

National Bureau of Statistics of China (2019). China Statistical Yearbook. Available at http://www.stats.gov.cn/tjsj/ndsj/2019/indexeh.htm. Accessed 15 July 2020.

Ng, E. S. W., \& Wyrick, C. R. (2011). Motivational bases for managing diversity: A model of leadership commitment. Human Resource Management Review, 21(4), 368-376.

Nunnally, J. C., \& Bernstein, I. H. (1994). Psychometric theory (3rd ed.). New York: McGraw-Hill.

Nyberg, A. (2010). Retaining your high performers: Moderators of the performance-job satisfaction-voluntary turnover relationship. Journal of Applied Psychology, 95(3), 440-453.

Oláh, L. S., Kotowska, I. E., \& Richter, R. (2018). The new roles of men and women and implications for families and societies. In A Demographic perspective on gender, family and health in Europe (pp. 41-64). Cham: Springer.

Peterson, D. K. (2004). The relationship between perceptions of corporate citizenship and organizational commitment. Business \& Society, 43(3), 296-319.

Peterson, M., Ekici, A., \& Hunt, D. M. (2010). How the poor in a developing country view business' contribution to quality-of-life 5 years after a national economic crisis. Journal of Business Research, 63(6), 548-558. 
Pettersson, T. (2006). Religion in contemporary society: Eroded by human wellbeing, supported by cultural diversity. Comparative Sociology, 5(2-3), 231-257.

Podsakoff, P. M., Mackenzie, S. B., Paine, J. B., \& Bachrach, D. G. (2000). Organizational citizenship behaviors: A critical review of the theoretical and empirical literature and suggestions for future research. Journal of Management, 26(3), 513-563.

Prem, R., Kubicek, B., Diestel, S., \& Korunka, C. (2016). Regulatory job stressors and their within-person relationships with ego depletion: The roles of state anxiety, selfcontrol effort, and job autonomy. Journal of Vocational Behavior, 92, 22-32.

Ragin, C. C. (1994). Constructing social research: The unity and diversity of method (Sociology for a new century). Newbury Park, CA: Pine Forge Press.

Ragin, C. C. (2000). Fuzzy-set Social Science. Chicago, IL: The University of Chicago Press.

Ragin, C. C. (2006). Set relations in social research: Evaluating their consistency and coverage. Political Analysis, 14(3), 291-310.

Ragin, C. C. (2008). Redesigning social inquiry: Fuzzy sets and beyond. Chicago and London: University of Chicago Press.

Rego, A., Leal, S., Cunha, M. P., Faria, J., \& Pinho, C. (2010). How the perceptions of five dimensions of corporate citizenship and their inter-inconsistencies predict affective commitment. Journal of Business Ethics, 94(1), 107-127.

Shepley, M. M., Watson, A., Pitts, F., Garrity, A., Spelman, E., Fronsman, A., \& Kelkar, J. (2017). Mental and behavioral health settings: Importance \& effectiveness of environmental qualities \& features as perceived by staff. Journal of Environmental Psychology, 50, 37-50.

Singhapakdi, A., Lee, D. J., Sirgy, M. J., \& Senasu, K. (2015). The impact of incongruity between an organization's CSR orientation and its employees' CSR orientation on employees' quality of work life. Journal of Business Research, 68(1), 60-66.

Sonnentag, S., \& Binnewies, C. (2013). Daily affect spillover from work to home: Detachment from work and sleep as moderators. Journal of Vocational Behavior, 83 (2), 198-208.

Subramaniam, G., Tan, P. L., Maniam, B., \& Ali, E. (2013). Workplace flexibility, empowerment and quality of life. Procedia-Social and Behavioral Sciences, 105, 885-893.

Thompson, C. A., \& Prottas, D. J. (2006). Relationships among organizational family support, job autonomy, perceived control, and employee wellbeing. Journal of Occupational Health Psychology, 11(1), 100-118.

To, C. K. M. (2016). Collaboration modes, preconditions, and contingencies in organizational alliance: A comparative assessment. Journal of Business Research, 69 (11), 4737-4743.

Tomlinson, J., Baird, M., Berg, P., \& Cooper, R. (2018). Flexible careers across the life course: Advancing theory, research and practice. Human Relations, 71(1), 4-22.

Turban, D. B., \& Greening, D. W. (1997). Corporate social performance and organizational attractiveness to prospective employees. Academy of Management Journal, 40(3), 658-672.
Unanue, W., Vignoles, V. L., Dittmar, H., \& Vansteenkiste, M. (2016). Life goals predict environmental behavior: Cross-cultural and longitudinal evidence. Journal of Environmental Psychology, 46, 10-22.

Valentine, S., Godkin, L., Fleischman, G. M., \& Kidwell, R. (2011). Corporate ethical values, group creativity, job satisfaction and turnover intention: The impact of work context on work response. Journal of Business Ethics, 98(3), 353-372.

Van Knippenberg, D., van Ginkel, W. P., \& Homan, A. C. (2013). Diversity mindsets and the performance of diverse teams. Organizational Behavior and Human Decision Processes, 121(2), 183-193.

Walton, R. (1974). Improving the quality of work life. Harvard Business Review, 52(3), 12.

Wilensky, H. L. (1960). Work, careers, and social integration. International Social Science Journal, 12(4), 543-560.

Woodside, A. G. (2013). Moving beyond multiple regression analysis to algorithms: Calling for adoption of a paradigm shift from symmetric to asymmetric thinking in data analysis and crafting theory. Journal of Business Research, 66(4), 463-472.

Woodside, A. G. (2016). The good practices manifesto: Overcoming bad practices pervasive in current research in business. Journal of Business Research, 69(2), 365-381.

Rachel W. Y. Yee is an Associate Professor, Institute of Textiles and Clothing, The Hong Kong Polytechnic University. She received a Ph.D. from The Hong Kong Polytechnic University. Her research interests include behavioral operations management, service management, and innovation management.

Maria-Jose Miquel-Romero is an Associate Professor of the Marketing Department at the University of Valencia, Spain. She has been Academic Director of the Master in Marketing and Market Research at the School of Business at the University of Valencia, and also coordinator of the Master in Marketing and Communication at the same University. Her research interests include advertising, private labels, omnichannel retailing, and consumer behavior. She has co-authored different book chapters and academic publications in indexed journals on the topics of her interest. She was a visiting scholar at the University of Glasgow, Scotland (UK), at University of Salford - Manchester (UK), and at HEC Montréal - Montreal (Canada).

Sonia Cruz-Ros (PhD) is Associate Professor of the Business Management Department at the University of Valencia, Spain. Nowadays, her main areas of interest are strategic management and entrepreneurship. She is author of several books about these topics, and she has participated in many national and international conferences. She has academic publications in indexed international journals on the topics of her interest. She has been Guest Editor of several international journals. She was Visiting Scholar at the University of Glasgow, Scotland (UK). 